\title{
Budget Management and Organizational Effectiveness in Nigeria
}

\author{
John Nkeobuna Nnah Ugoani \\ College of Management and Social Sciences, Rhema University, Ab Nigeria
}

\begin{abstract}
The study examined the relationship between budget management and organizational effectiveness. Budget management is a useful mechanism for enhancing managerial behavior and necessary in motivating managers towards the achievement of organizational objectives. Organizational effectiveness is the reflection of how well resources are used by management that results to productivity and overall profitability. Budget management reinforces planning, coordination, motivation, communication as well as top management action. The exploratory research design was used for the study, and through data analysis, it was found that budget management has positive correlation with organizational effectiveness. The study suggests that management at all levels and times must ensure that deviations from budget are checked to avoid mismanagement and enterprise failure.
\end{abstract}

Keywords: Budget accounting and reporting; Coordination; Management efficiency and effectiveness; Budgetary controls; Performance management; Top management.

(9) (1) CC BY: Creative Commons Attribution License 4.0

\section{Introduction}

The achievement of business prosperity requires efficient management of available resources through planning, organizing, directing, controlling and budgeting. Also, the strengths and weaknesses of the business must be identified and necessary corrective measures taken based on sound budgeting. Budgeting leads to management commitment to ensure organizational renewal and effectiveness. Budgeting also enhances accountability and transparency of transactions. According to Oladele et al. (2013), adequate transparency is critical to ensuring that resources are well managed for the benefit of all stakeholders. Broadly speaking, a budget is a plan of expected incomes, expenditures, standards and performance for a certain period of time. It is a tentative future plan of action, and not an end in itself. A budget is an estimate of the expected revenue and expenditure of individual, group, government or organization in a stated period of time, usually one year. It is used to control the allocation of revenues and other resources so that spending becomes rational (Ani, 1998; Ezeokonkwo, 1998). Budget Management (BM) therefore involves the control of budgetary goals. BM regulates a set of performance standards that can be compared to actual results. It is the checking, analysis, and control of organizational costs and expected expenditures necessary for the achievement of enterprise objectives. BM involves budgetary controls which is the establishment of budgets, relating the responsibilities of executives to the requirements of a policy, and the continuous comparison of actual with budgeted results either to secure by individual action, the objectives of that policy or provide a basis for its revision (Monwuba, 1995a). Good budget management leads to organizational effectiveness because bad management of money and other critical resources leads to serious shortfalls both in cash and other balance sheet components and this can put a business in severe pressure and real jeopardy. Organizational Effectiveness (OE) includes but is not limited to efficiency and profitability. Herman and Renz (2008), opine that $\mathrm{OE}$ is the concept of how effective an organization is in achieving the outcomes the organization intends to achieve. BM allows OE groups in organizations to directly concern themselves with several key areas such as talent management, leadership development, organization design and structure, development of balanced scorecards, introduction and implementation of change and transformation, and deploying better processes of the use of information and communication technology (ICT). OE thrives on appropriate allocation of financial and material resources to capture the key areas that help management to realize its objectives, and this cannot happen without effective BM. Monwuba (1995a), suggests that a budget usually allocates specific amounts of money and resources to various areas of the organization that require them. BM also keeps record of incoming revenues. To achieve OE, $\mathrm{BM}$ is involved in constantly balancing and maintaining good levels of resources without bursting the limit. BM spans the various functional areas of the business such as sales, production, purchasing, and research, among others. If $\mathrm{BM}$ is to be meaningful, then production and sales will be forced to consult and co-ordinate their efforts so that production meets sales requirements, likewise purchasing must consult and co-ordinate with production, so that targets can be achieved. Sound BM embraces full and proper communication of plan. Tentative plans have to be communicated to the functional managers and agreement has to be reached before budgets can become operational. This is important because actual results must be measured against budgets and variances communicated to the appropriate levels for management action. It relies on proper preparation and agreement of budget, the analysis and comparison of actual expenditures with targeted yardsticks, the reporting and action taken on adverse controllable variances, that assist management to be more financially aware of their actions and the areas of their actions, and the areas requiring special attention. Monwuba (1995a), asserts that, the timely analysis of actual expenditure and the preparation of variance provide a basis for budget evaluation and the determination of the financial health of the business. As corruption has its own motivations, it is believed that BM is needed in controlling it and ensuring high 
quality financial management which is ever critical for OE. Organization effectiveness is defined as the extent to which multiple goals are achieved. According to Gandhi and Sachdera (2018), an organization is said to be effective when it achieves its purpose and objective while providing maximum return to the society. Organizational effectiveness is often measure for area major perspectives. First the output perspective which involves profit, second the outcome perspective which relates to market share, in terms of share prices, and the third, when there is a decline in the employee turnover, reduction in absenteeism, as well as simultaneously increase in productivity. Scholars insist that it is multidimensional concept that cannot be measured with single factor (Price, 1972),

\subsection{Statement of the Problem}

A major problem of BM in Nigeria lies at the preparation stage that does not encourage the participation of the users. Participation is a key aspect of the budget process and there is also need for budget education. Accountants and managers who often prepare budgets should encourage other managers and lay people who use and operate the budget to understand the financial implications of their plans and so able to investigate and report on deviations from target, at the appropriate time, and at the appropriate level. For the budget to be correctly applied as a positive managerial technique to achieve OE, it is important that all people who use and operate it are made aware of its importance to the organization. Often people speak of budgets and BM without remembering the context of organization fit. As with any other aspects of management, BM may not help the business in achieving OE if it is poorly handled, to minimize the problem, the matter of organization fit must be reorganized. According to Monwuba (1995b), a full system of budgetary control may not be appropriate in certain business. In particular, rapidly changing technology and or market forces may render the traditional twelve months detailed budget unhelpful. He asserts that in a business facing very dynamic conditions, it may be that planning and control must be limited to crucial areas, such as sales and overall cash flow, but that detailed cost budgets may be unnecessary. However, this does not suggest that control is unimportant in fast changing organizations, only that full budgetary control may be inappropriate to overcome the challenges therefore, managers should ensure that the budget system serves the needs of the organization. To achieve OE, the budget system should be designed around the peculiar needs of the organization.

\subsection{Conceptual Approach of the Study}

An important requirement for every business is to grow and prosper. Business prosperity and profitability depend a great deal on the effectiveness and efficiency of its management. BM is very critical to evaluate an organization's managerial efficiency and effectiveness, using several generally accepted management techniques. Among the techniques used in BM include budget accounting and reporting (BAR). Budget as a plan quantified in monetary terms, prepared and approved prior to a defined period of time, usually showing planned income to be generated and or expenditure to be incurred during that period and the capital to be employed to attain a given objective is a critical component for the survival of a business enterprise. BM helps in the vital appraisal of existing conditions that help in taking decisions about future conditions of the business and the macroeconomic environment. This study is imperative at this time when it is realized that many enterprises suffer from poor budgetary preparation, control, and management, and again where not many researchers have addressed the topic with particular reference to Nigeria. BM is subsumed by the main activities of management, embracing to plan, organize, direct, co-ordinate, motivate and control, but the issue of BM requires particular discussion because of its central role to OE. Very importantly, since the prosperity of a business depends ultimately upon its financial soundness the matter of budgeting, budgeting control, and BM make a huge contribution to its effectiveness. A budget is a very useful tool for enhancing managerial behavior and motivating managers to perform in line with the organizational objectives. According to Drury (2008), a budget helps managers in managing and controlling the activities for which they are responsible. He opines that by comparing the actual results with the budgeted amounts for different categories of expenses managers can ascertain which costs do not conform to the original plan and thus require their attention. Through this process, management is able to operate a system of management by objectives and able better to focus attention on major deviations from budget. It cannot be over emphasized that BM is a critical ingredient in support of the present global agenda of green and sustainable financial management that is imperative for the economic development of the emerging economies of Africa (Amadi, 2018),

\subsection{Objective of the Study}

The study was designed to explore the relationship between BM and OE in Nigeria.

\subsection{Significance of the Study}

The study will help students in the areas of management and social sciences to appreciate the relevance of BM on OE. It will also help other researchers to do more work in the area, and also enable top management and the general public to review their approach toward BM.

\subsection{Hypothesis}

Ho: There is no relationship between $\mathrm{BM}$ and $\mathrm{OE}$ in Nigeria.

Hi: There is a relationship between BM and OE in Nigeria. 


\section{Literature Review}

$\mathrm{BM}$ is designed to facilitate the control of an organization's activities by comparing targets with actual results. $\mathrm{BM}$ is also a means of communicating, motivating and coordinating organizational activities. Again, it performs directional function by providing guide as to the intended direction of a business or organization during the budget period in terms of priority, focus and attention. It equally does the developmental function by helping to harmonize business plan with the master budget (Lucey, 1996; Omolehinwa, 2002). Management at all levels; particularly top management has a responsibility to enforce BM in organizations. This commitment is necessary to enable it confront the principal budget factor otherwise known as limiting factor or key factor, which at any time poses as an overriding planning limitation on the activities of the organization. According to Monwuba (1995a), the principal budget factor may be production capacity, sales availability or finance, skilled labour, suppliers of raw materials, or lack of space. Where a single binding constraint can be identified, then the general objective of maximizing contribution can be achieved by selecting the alternative which maximizes contribution. Identifying and dealing with the budget factor in $\mathrm{BM}$ is key to achieving the desired level of $\mathrm{OE}$.

\subsection{Budgetary Control}

Budgetary control is a central component of BM. Budgetary control is a system of controlling costs which includes the preparation of budgets, coordinating the departments and establishing responsibilities, comparing actual performance with the target. Budgetary control serves as a check of performance against authorization. All approved estimates in a budget should not be regarded as authorization to commit organization's funds, but only indicative of what may be spent in a particular case. A good system of budgetary control ensures that variances are used to provide a guideline for control action by individual managers or a guideline for altering the master budget in the light of the actual event. For effective budgetary control, Monwuba (1995b), advocates the use of Budget Manual, especially in large organizations. The Budget Manual is a document which sets out the standards governing the responsibilities of persons, and the procedures, forms, and records relating to the presentation and use of budget manual are to ensure proper control of budget centres. A budget centre of an organization is identified and known also as a cost centre. The centre is the responsibility area of a manager so that the manager is aware of the budget performance as and when it occurs and by how much his centre has over-performed, or under-performed, in the event of adverse variances to enable the manager initiate remedial managerial actions (FBN Plc, 1999). BM ensures that the organization also has necessary cash at hand to meet its daily obligations, without which its effectiveness will be jeopardized (Ugali, 2004). BM and budgetary control are necessary for OE because a properly managed budget can promote sustainable profitability for the organization. According to Assey (2014), budgets play important managerial roles necessary for organization. He opines that a well formulated budget system enables the organization to reach its goals more successfully. The action that follow management decisions usually involve different areas of business such as: marketing, sales, production, purchasing, accounting, and finance functions, and it is necessary that management should coordinate these interrelated areas effectively based on sound managerial control. However, if management fails to do this, managers may each take decisions that will not be in the general interest of the organization and which may not align with its reputation and overall effectiveness.

\subsection{Budget Accounting and Reporting (BAR)}

Sound BAR is essential for effective budget management control and oversight of organizational performance. Accurate, timely, and good record keeping, accounting, and reporting of income and expenditure information is essential for enforcing accountability in the BM process. Modern integrated accounting system facilitates tracking of income and expenditure and matching of information from alternative sources. An integrated financial management information system (IFMIS) is also necessary to enhance BM operations, because inaccurate and incomplete recording of transactions due to technical weaknesses or intentional disregard for accuracy and comprehensiveness can obscure fraudulent activity; impede auditing, and restrict management action and control. According to Dorotinsky and Pradhan (2007), every transaction should be recorded, including loans, disbursements, commitments and payments. The accounting system is at the heart of the IFMIS. Any weaknesses in accounting practices and in reconciliation of enterprise accounts introduce vulnerabilities in the BM process by decreasing the comprehensiveness of fiscal reports and data essential for audit and management control. For effective BM, BAR is critical for internal control. Internal control is commonly understood to mean the procedures used within an organization to prevent or detect improper use of funds and other resources. Modern internal control is understood more as a process designed to provide reasonable assurance regarding achievement of organizational objectives, in compliance with statutes, policies and the budget. Internal control processes involve the control environments, assessment of risks from various operating or expenditure control activities, information and communication and monitoring. Typical internal control activity includes formal transactions approvals, authorizations, verifications, reconciliations, reviews of performance, security of assets, segregation of duties, and information system control. BAR enhances the efficiency of cash management in BM process. Cash management is important for OE and starts from the commitment stage, when purchase orders are placed or contracts are signed; the verification stage; when the budget centres confirm the delivery of the goods and checks the bill; payment authorization; in which the chief executive officers (CEOs) authorize the payment and the payment stage; when the bill is paid by cash, cheque or by bank or electronic transfer. BAR as a managerial control technique is now widely used in both government, commercial and industrial organizations. It is an important mechanism as BM has become a veritable approach for management in motivating and achieving organizational goals and effectiveness. To ensure OE, the quality of audits, 
legal mandates on the scope of audits, and follow-up on audit recommendations, including full investigation and penalties for identified fraudulent behaiour, and essential areas requiring the focus of BM (Dorotinsky and Pradhan, 2007). BM results in management commitment to use audit recommendations in strengthening OE. According to Enofe et al. (2013), top management support and commitment to change play a crucial role in organizational renewal and effectiveness. It drives transparency in revenue collection and expenditure. According to Oladele et al. (2013), transparency is critical to ensuring that resources are well managed for the benefit of all stakeholders. BAR is a major component of BM because according to Akanwa (1997), when resources are properly managed, it leads the organization to achieving its goals. He asserts that organizations are consciously created to accomplish certain objectives and these goals when achieved result to OE. He posits that to inquire into effectiveness is to ask how well an organization is doing relative to some set standards or budgets. According to him, OE is the measure of the extent to which an organization applies its resources efficiently and without placing undue strain upon its members. According to Nzotta (2002), the budget management process translates the organizational objectives into specific plans and tasks, it communicates the organizational objectives and plans and the progress made towards meeting these objectives over time. The process brings about efficient time management, and ensures that the performance of all levels of management are systematically reported and monitored. BM as a top priority of top management is linked with, and ensures that the whole budgetary control leads to cost minimization, profit maximization, a higher level of efficiency and OE. BM can be seen as an important work value which underscores the principle of planning, organizing, staffing, directing, co-ordinating, reporting and budgeting (POSDCORB) to OE. (Amah and Ahiauru, 2014; Rana et al., 2016) BM and OE are closely related because according to Gandhi and Sachdera (2018), OE is more than profitability and includes factors such as employee satisfaction, motivation, goal integration and group functioning.

\section{Methodology}

\subsection{Research Design}

The exploratory research design was used for the study. The exploratory design is historical in nature, and does not usually require a large sample or a structured questionnaire (Asika, 2004; Brannen, 2005).

\subsection{Sources of Data}

Data were generated through secondary and primary sources. Secondary data are information that has been previously collected for some other purposes other than the research project at hand, whereas primary data are information gathered and assembled specifically for the research objectives at hand.

\subsection{Sample Frame}

The sample frame comprised of individuals interested in BM and OE in Nigeria.

\subsection{Sample Technique}

Purposive sampling technique was used to select the sample and there were 72 respondents composed of 20 females and 52 males ranging in age between 18 and 70. The technique involves the selection of units based on factors other than random chance (Tiwari and Saxena, 2016).

\subsection{Sample Size}

For the purpose of the study, 72 respondents were taken.

\subsection{Area of Study}

The study was conducted in South East Nigeria, comprised of 5 states, out of the 36 states in Nigeria. The area has a high number of private and public organizations that are involved in the budget process.

\subsection{Data Analysis}

Data analysis was done by descriptive and correlation statistical methods and the result presented in tables.

\section{Presentation of Result}


Table-1. Demographic Profile of the Sample ( $n=72)$

\begin{tabular}{l|l|l}
\hline Category & Number & Percent \\
\hline Gender & & \\
\hline Male & 52 & 72 \\
\hline Female & 20 & 28 \\
\hline Work experience & & \\
\hline $1>3$ years & 14 & 20 \\
\hline $2>5$ years & 12 & 17 \\
\hline $5>10$ years & 17 & 23 \\
\hline$>10$ years & 29 & 40 \\
\hline Educational level & & \\
\hline Secondary & 6 & 8 \\
\hline Diploma & 39 & 54 \\
\hline Degree & 27 & 38 \\
\hline
\end{tabular}

As per Table 1, the sample for this study included middle and senior managerial employees of different organizations in Nigeria.

Table-2. Descriptive Statistics

\begin{tabular}{l|l|l|l|l|l}
\hline Budget Management (BM) & $\mathbf{n}$ & Minimum & Maximum & Mean & S Deviation \\
\hline Budget Planning (BP) & 72 & 1.00 & 5.0 & 4.41 & .887 \\
\hline Budget Control (BCL) & 72 & 1.00 & 5.0 & 4.03 & 1.032 \\
\hline Budget Monitoring (BMT) & 72 & 1.00 & 5.0 & 4.21 & 1.042 \\
\hline Budget Communication (BCC) & 72 & 1.00 & 5.0 & 3.90 & 1.012 \\
\hline Budget Evaluation (BE) & 72 & 1.00 & 5.0 & 3.05 & .964 \\
\hline Budget Coordination (BCO) & 72 & 1.00 & 5.0 & 3.11 & 1.051 \\
\hline Budget Motivation (BN) & 72 & 1.00 & 5.0 & 2.14 & .943 \\
\hline Management Action (MA) & 72 & 1.00 & 5.0 & 2.67 & 1.401 \\
\hline
\end{tabular}

Table 2 showed the results of descriptive statistics. A higher mean value generally means that there is a higher level of measured construct. Since this study was exploratory in nature, the collected data were further analyzed using the Bivariate Correlation Test. The Bivariate Correlation Test computes Pearson's correlation coefficient, and measures how variables or rank orders are related. Pearson's correlation coefficient is a measure of linear association. The correlation coefficient value (r) ranging from 0.10 to 0.29 is considered weak, from 0.30 to 0.49 is considered medium and from 0.50 to 1.0 is considered strong.

Table-3. Correlation Between $\mathrm{BM}$ and $\mathrm{OE}$

\begin{tabular}{l|l|l|l|l|l|l|l|l|l}
\hline & BP & BCL & BMT & BCC & BE & BCO & BM & MA & \\
\hline OE & & & & & & & & & \\
\hline BP & 1.0 & & & & & & & & \\
\hline BCL & 0.222 & 1.0 & & & & & & & \\
\hline BMT & 0.123 & 0.060 & 1.0 & & & & & & \\
\hline BCC & 0.152 & $0.599^{*}$ & 0.152 & 1.0 & & & & & \\
\hline BE & 0.088 & 0.100 & $0.596^{*}$ & 0.240 & 1.0 & & & & \\
\hline BCO & 0.024 & $0.37^{*}$ & $* 0.143$ & $0.276^{*}$ & $0.545^{*}$ & 1.0 & & & \\
\hline BN & 0.134 & $0.419^{*}$ & 0.122 & 0.143 & 0.134 & 0.176 & 1.0 & & \\
\hline MA & $0.28^{*}$ & 0.134 & 0.187 & 0.295 & 0.141 & $0.337^{*}$ & $0.545^{*}$ & 1.0 & \\
\hline & $0.219^{*}$ & $0.375^{*}$ & 0.143 & 0.13 & $0.575^{*}$ & $0.632^{*}$ & 0.696 & $0.518^{*}$ & 1.0 \\
\hline
\end{tabular}

Note: * Correlation is significant at the 0.05 level (two-tailed); ** correlation is significant at the 0.01 level (two-tailed).

Table 3 showed the correlations between BM and OE. As can be seen, correlations between the BM factors and OE ratings were high $(0.518$ to $0.696, \mathrm{P}<05)$, and as expected, it was confirmed that $\mathrm{BM}$ has significant positive correlation with $\mathrm{OE}$. This is the objective of the study.

\subsection{Discussion}

From the correlation analysis, it was proved that BM has positive correlation with OE. The result supports, the earlier findings of Assey (2014), that effective budgeting process promotes organizational profitability. BM is concerned with how efficient resources are managed. This result also supports the views of Akanwa (1997), among others that proper management of resources leads to OE. Budget is one of the most widely used tools for planning and controlling the activities of organizations. And because organizations operate using critical resources like: human, financial, physical, among others, BM is used to ensure that these resources are efficiently utilized to promote OE. BM enhances transparency and accountability of organizational activities and also ensures a critical balance between budget and actual performance. Good BM enhances the quality of cash management to ensure that 
the organization operates at the optimum level. For effectiveness, organizations seek for the best ways to employ the cash at their disposal. Cash management is the optimal use of cash as an asset, and this may not be possible in the absence of sound BM. According to Ugali (2004), cash management involves managing the monies of the organization in order to attain maximum cash availability and maximum interest income on all idle funds. Budgeting for and managing cash are essential because cash shortage will dislocate organizational daily operations, while excessive cash will just remain idle at a cost without contributing anything towards OE. Cash management helps to improve the internal transparency of the budget process. BM ensures management control and oversight of organizational expenditures for improved effectiveness. Management oversight of budgeted expenditure, deviations from approved budget for expenditures and revenues is the first step in flagging down potential occurrences of fraud and mismanagement. Improving management oversight helps in the detection of fraudulent behavior, and responding to fraud, instituting procedures to follow-up on audit findings and recommendations, strengthening the planning and monitoring expenditure and implementing procedures to promote accountability, responsibility and transparency. $\mathrm{BM}$ when properly instituted remains the backbone of organizational accountability transparency and effectiveness because it seeks to block all the avenues for fraud, diversion, corruption and manipulation, detrimental to OE. BM provides the opportunity to strengthen internal consistency and adherence to budgetary procedures that result to full compliance with ethical standards, rules, regulations and laws that enable organizations to win competitive advantage, and ultimately bring about OE. Assey (2014), suggests that there is a need to integrate strategic management and budgeting, and that budgets must be aligned with the organization's strategies, including strategic planning, and performance management process so as to achieve overall OE.

\subsection{Scope for Further Study}

Further study should check the relationship between weak BAR processes and business failures in Nigeria to determine the effect on huge corporate failures like the Cadbury case in Nigeria (Okaro and Okafor, 2013).

\subsection{Recommendations}

i) Management must at all times ensure that deviations from budget are properly checked. This is important to avoid mismanagement and business failures.

ii) Management oversight should be an important responsibility of too management to enhance the quality of BM.

iii) Adequacy of cash, to meet organizational daily operations should be a major concern of management so that the organizational reputation is not jeopardized.

iv) Management must recognize a budget as a means to an end and to insist on improving the quality of budget preparation and its understanding by the users to bring about successful implementation and OE.

v) Governments need to turn a positive page on BM so as to reduce corruption, fraud, theft, and enhance the quality of public expenditures in Nigeria for the benefit of the people.

\section{Conclusion}

A budget is an estimate of expenses and incomes of an organization; thus BM helps to ensure that organizational resources are efficiently employed to promote organizational profitability and effectiveness. To achieve this relies on effective budgetary control, and BAR. BAR is very important for effective budget management control and oversight of organizational performance. BAR as a managerial control mechanism is today widely used in both government, commercial and industrial organizations for the ultimate promotion of efficiency, profitability and effectiveness. The exploratory research design was used for the study. Data were analyzed through descriptive and correlation statistical methods, using the SPSS. The result of the study showed that BM has positive relationship with OE. The result gives credence to the findings of Assey (2014), Akanwa (1997), Dorotinsky and Pradhan (2007), among others, that BM is a prerequisite for OE. This is the crux of this study.

\section{References}

Akanwa, P. U. (1997). Fundamentals of Human Resource Management in Nigeria. Owerri Kosoko Press Limited.

Amadi, B. (2018). Listed companies henceforth must publish Sustainability Report - NSE West Africa Business News. 5(270): 15.

Amah, E. and Ahiauru, A. (2014). Shared values and organizational effectiveness, A study of the Nigerian banking industry. Journal of Management Development, 33(7): 694-708.

Ani, W. U. (1998). Government \& Public Sector Accounting, A Professional Approach. Enugu Immaculate Publications Ltd.

Asika, N. (2004). Research methodology. A process approach lagos. Mukugamu and Brothers.

Assey, D. D. (2014). Effectiveness of budgeting process in achieving organizational goals, A case of temess. Unpublished MBA dissertation, The Open University of Tanzania.

Brannen, J. (2005). Mixing methods, The entry of qualitative and quantitative approaches in to the research process. International Journal of Social Research Methodology, 8(3): 173-84.

Dorotinsky, W. and Pradhan, S. (2007). Exploring corruption in public financial management. In J. E. Campos and S. Pradhan (eds) The many faces of corruption, Tracking vulnerabilities at the sector level. The World Bank: Washington, D.C. 267.

Drury, C. (2008). Management and cost Accounting. 7th edn: Book Power: UK.: 
Enofe, A. O., Mgbame, C. J., Osa-Erhabor, V. E. and Ehiorobo, A. J. (2013). The role of internal audit in effective management in public sector. Research Journal of Finance and Accounting, 4(16): 162 - 68.

Ezeokonkwo, R. O. (1998). Public finance for tertiary institutions, A modern approach. Fountain Publishers (Nig.): Awka.

FBN Plc (1999). Branch management, Budgeting and budgetary control, Enugu area office Nigeria.

Gandhi, M. and Sachdera, T. (2018). Impact of diverse values of employees on organizational effectiveness. Amity Business Journal, 7(1): 11.

Herman, R. D. and Renz, D. O. (2008). Advancing non profit organizational effectiveness research and theory, Nine theses. Nonprofit Management \& Leadership, 18(4): 399-415.

Lucey, T. (1996). Management Accounting. 4th edn: ELST.: UK,.

Monwuba, A. O. (1995a). Auditing and Investigations, 76 Questions and Answers. Onitsha Fortune Printing Ind. Ltd.:

Monwuba, A. O. (1995b). Management Accounting. IBS Press Nigeria: Enugu.

Nzotta, S. M. (2002). Corporate Financial Decisions Owerri. Olliverson Industrial Publishers.

Okaro, S. C. and Okafor, G. O. (2013). Drivers of audit failure in Nigeria-Evidence from Cadbury (Nigeria) Plc. Research Journal of Finance and Accounting, 4(6): 14-17.

Oladele, R., Aderemi, A. A. and Idode, P. (2013). Revenue generation and transparency in Nigeria Oil and Gas industry, (Position of Nigeria Extractive Industries Transparency Initiative (Neiti). Research Journal of Finance and Accounting, 4(6): 99 - 144.

Omolehinwa, A. (2002). Work out management Accounting, Notes and worked examples. 2nd edn: Panaf Publishing Inc.: Lagos.

Price, J. L. (1972). The study of organizational effectiveness. The Sociological Quarterly, 13(1): 1-6.

Rana, G., Rastogi, R. and Garg, P. (2016). Work values and its impact on managerial effectiveness. A relationship in Indian context. Vision, 20(4): 300-11.

Tiwari, N. and Saxena, R. K. (2016). A study of factors and preferences towards investment decision for life insurance policy. Amity Business Journal, 5(1): 69-75.

Ugali, K. O. (2004). Managing cash level. LMDS Journal of Accountancy, 2(1): 32-36. 